\title{
Characterization of Nicotinic Receptors in Chick Retina Using a Snake Venom Neurotoxin That Blocks Neuronal Nicotinic Receptor Function
}

\author{
Ralph H. Loring,, ${ }^{1, a}$ Elias Aizenman, ${ }^{2}$ Stuart A. Lipton, ${ }^{2}$ and Richard E. Zigmond ${ }^{2}$ \\ 'Department of Biological Chemistry and Molecular Pharmacology, and 'Department of Neurology, Harvard Medical \\ School, and Children's Hospital, Boston, Massachusetts 02115
}

\begin{abstract}
Nicotinic receptor function has been described in the retinas of a variety of vertebrate species. Neuronal bungarotoxin (NBT, also known as bungarotoxin 3.1, toxin F, or $\kappa$-bungarotoxin) blocks nicotinic receptors in several neuronal preparations, while the neuromuscular antagonist $\alpha$-bungarotoxin (BGT) fails to block most of these receptors. NBT (100 nM), but not BGT (10 $\mu \mathrm{M})$, substantially blocks nicotinic function on ganglion cells in intact chick retina. ${ }^{125}$ /-NBT binds to 2 sites in homogenates of chick retina; one site that is shared with BGT ( $K_{d}=5-7 \mathrm{nM}, B_{\max } \sim 500 \mathrm{fmol} / \mathrm{retina}$ ) and one which is not $\left(K_{d}=2-3 \mathrm{nM}, B_{\max } \sim 100 \mathrm{fmol} / \mathrm{retina}\right)$. ${ }^{125}$ - NBT binding to the NBT-specific site (binding in the presence of $1 \mu \mathrm{m}$ unlabeled BGT) is localized to 2 bands in the inner plexiform layer, corresponding to regions richly innervated by neurons containing immunoreactivity for choline acetyltransferase. Furthermore, this binding is blocked by competitive nicotinic agonists and antagonists, but nicotine or other nicotinic agonists do not displace ${ }^{125 \mid}$-NBT binding with very high affinity relative to the displacement of ${ }^{3} \mathrm{H}$-nicotine reported by others in brain. Thus, of the 2 NBT binding sites, the site not recognized by BGT most likely represents functional nicotinic receptors in the chick retina, but these receptors have relatively low affinity for nicotinic agonists, similar to nicotinic receptors found in autonomic ganglia.
\end{abstract}

Nicotinic transmission is known to be important in sensory processing in the retinas of the rabbit (Masland and Ames, 1976; Ariel and Daw, 1982a, b) and cat (Ikeda and Sheardown, 1982). In addition, nicotinic function is believed to play an important physiological role in retinas of other species (reviewed by Neal, 1983; Puro, 1985). Recently, we have demonstrated that isolated ganglion cells from rat retina possess functional nicotinic receptors (Lipton et al., 1987), suggesting that the nicotinic ef-

Received July 18, 1988; revised Nov. 15, 1988; accepted Dec. 7, 1988

We thank Dr. Miles Fpstein for generously supplying rabbit antiserum to chicken choline acetyltransferase, Dr. Cathy Sasek for help with the immunohistochemical staining, and James Bernhard for invaluable technical assistance. This work was supported in part by U.S. Public Health Service Research Grants NS 22472, NS 12651, NS 00879 , and EY 05477 from the National Institutes of Health and by a Fight for Sight Postdoctoral Fellowship, Fight for Sight, Inc., New York, New York. S.A.L. is supported by an established investigatorship of the American Heart Association and R.E.Z. by a Research Scientist Award (MH 00162).

Correspondence should be addressed to Dr. Richard E. Zigmond at his present address: Center for Neurosciences, Case Western Reserve University, School of Medicine, 2119 Abington Rd., Cleveland, OH 44106.

a Present address: Department of Pharmacology, Northeastern University, 360 Huntington Ave., Boston, MA 02115.

Copyright (C) 1989 Society for Neuroscience $0270-6474 / 89 / 072423-09 \$ 02.00 / 0$ fects of ACh in the retina occur, in part, directly on ganglion cells. Nicotinically driven ganglion cells are thought to be involved in the detection of stimulus motion (Ariel and Daw, 1982a, b). In addition, nicotinic receptors may mediate trophic functions affecting process outgrowth in the retina (Lipton et al., 1988).

Snake venom neurotoxins, such as $\alpha$-bungarotoxin (BGT), have proven invaluable in characterizing nicotinic receptors from muscle. Although BGT has been used as a marker for neuronal nicotinic receptors (e.g., Vogel and Nirenberg, 1976; Wang and Schmidt, 1976), in most cases, BGT fails to block nicotinic receptors on neurons (reviewed by Chiappinelli, 1985). For example, we have found that $10 \mu \mathrm{M}$ BGT has no effect on nicotinic receptor function found on isolated ganglion cells from rat retina (Lipton et al., 1987).

Experiments by Chiappinelli and Zigmond (1978) were the first to suggest that Bungarus multicinctus venom contains neurotoxins other than BGT that block neuronal nicotinic receptors. Ravdin and Berg (1979) subsequently purified such a toxin, which they referred to as bungarotoxin 3.1. Bungarotoxin 3.1 has an apparent molecular weight on SDS-PAGE of $6.5 \mathrm{kDa}$ and blocks nicotinic function in cultures of chick ciliary neurons. Similar neurotoxins, referred to as toxin F (Loring et al., 1984) and $\kappa$-bungarotoxin (Chiappinelli, 1983) have also been purified. Recently, we established by amino acid sequence data and other biochemical properties that bungarotoxin 3.1 , toxin $F$, and $\kappa$-bungarotoxin are, in fact, the same neurotoxin (Loring et al., 1986). Therefore, the term "neuronal bungarotoxin" has recently been suggested as a common name to describe this neurotoxin (Lindstrom et al., 1987). In the present study, we have examined the effect of neuronal bungarotoxin (NBT) on nicotinic receptors in the chick retina and have examined the binding properties of ${ }^{125}$ I-NBT to this CNS preparation.

\section{Materials and Methods}

Electrophysiological measurements. Depolarizations in whole chick retinas due to exogenously applied dimethylphenylpiperazinium (DMPP) were recorded using a modification of a recording technique developed for autonomic ganglia (Loring, 1985). Eyecups were prepared from 27-d-old chicks and constantly perfused with Tyrode's solution $(130 \mathrm{~mm}$ $\mathrm{NaCl}, 3 \mathrm{~mm} \mathrm{KCl}, 20 \mathrm{~mm} \mathrm{NaHCO}_{3}, 17 \mathrm{~mm}$ dextrose, bubbled with $95 \%$ $\mathrm{O}_{2} / 5 \% \mathrm{CO}_{2}, 0.01 \% \mathrm{wt} / \mathrm{vol}$ phenol red) containing $10 \mathrm{mM} \mathrm{MgCl}_{2}$ and $0.1 \mathrm{mM} \mathrm{CaCl}_{2}$ to inhibit synaptic interactions. The eyecup was supported in a plastic chamber. $\mathrm{A}$ unipolar suction electrode $\left(\mathrm{Ag}^{+} / \mathrm{AgCl}\right)$ was attached to the cut optic nerve through a slit in the perfusion chamber. Excess medium was removed via vacuum suction. The perfusion rate was approximately $4 \mathrm{ml} / \mathrm{min}$, and the volume in the eyecup was about $100 \mu \mathrm{l}$. Antagonists were perfused into the eyecup, but agonists were 
added as a $50 \mu \mathrm{l}$ drop directly into the eyecup solution. The DC potential between the suction electrode on the optic nerve stump and a unipolar $\mathrm{Ag}^{+} / \mathrm{AgCl}$ electrode placed within the eyecup solution was amplified and continually monitored on an oscilloscope. An additional $\mathrm{Ag}^{+} / \mathrm{AgCl}$ electrode placed in the eyecup solution and connected to ground served to reduce electrical noise. Both electrodes placed in the eyecup solution were enclosed in Tyrode-filled glass capillaries to isolate the electrodes from the effects of changes in the fluid level, and all electrode leads were shielded. Experiments were performed at ambient temperature under normal room lighting.

Binding assays. ${ }^{125}$ I-NBT and ${ }^{125}$ I-BGT were iodinated as previously described (Loring and Zigmond, 1987). NBT was purified by the method of Loring et al. (1986) and BGT was obtained from Biotoxins Inc. Retinas from embryos and from 1-4-d-old posthatch chicks were dissected in Eagle's minimum essential medium (GIBCO) and then frozen in liquid $\mathrm{N}_{2}$ and stored at $-70^{\circ} \mathrm{C}$ prior to use. Embryonic retinas were derived from pathogen-free eggs (SPAFAS), while those from hatched chicks were from white leghorn cockerels obtained from local hatcheries.

Retinas were homogenized in PBS (10 $\mathrm{mM} \mathrm{NaPO}_{4}$, pH 7.5, $155 \mathrm{~mm}$ $\mathrm{NaCl}$ ) containing $5 \mathrm{~mm}$ phenylmethylsulfonyl fluoride, $1 \mathrm{~mm}$ EGTA, 1 $\mathrm{mM}$ EDTA and $1 \mathrm{mg} / \mathrm{ml} \mathrm{BSA}$, unless otherwise noted. Typically, retinal homogenate was incubated with radioactively labeled toxin and any competing ligands in a final volume of $100 \mu \mathrm{l}$ at room temperature and then layered over $0.9 \mathrm{ml}$ of centrifugation buffer $(0.1 \mathrm{M} \mathrm{NaCl}, 10 \mathrm{~mm}$ $\mathrm{NaPO}_{4}, \mathrm{pH} 7.5,0.32 \mathrm{M}$ sucrose, $1 \mathrm{~mm} \mathrm{MgCl}, 1 \% \mathrm{BSA}$ ) at $4^{\circ} \mathrm{C}$ in a 1.5 $\mathrm{ml}$ Eppendorf centrifuge tube. After centrifugation for $3 \mathrm{~min}$ at $4^{\circ} \mathrm{C}$, the supernatant was aspirated and the pellet washed twice and centrifuged for $3 \mathrm{~min}$ each time with $0.6 \mathrm{ml}$ centrifugation buffer. After removing the supernatant, the radioactivity bound to the pellet was determined in a gamma counter.

Because of the possibility that the centrifugation assay may underestimate the portion of rapidly dissociating ${ }^{225}$ I-NBT due to the lengthy centrifugation steps, one cxpcriment to detcrminc the dissociation rate of ${ }^{125}$ I-NBT was performed using a filtration assay. Retinal homogenate was incubated with radioactively labeled toxin at room temperature. Aliquots $(100 \mu \mathrm{l})$ were then filtered through a Whatman $\mathrm{GT} / \mathrm{C}$ fiberglass filter using 3 rinses ( $3 \mathrm{ml}$ each) of $150 \mathrm{~mm} \mathrm{NaCl}, 10 \mathrm{~mm} \mathrm{NaPO}, \mathrm{pH}$ 7.5 , and $0.1 \mathrm{mg} / \mathrm{ml} \mathrm{BSA} \mathrm{at} 4^{\circ} \mathrm{C}$. The total filtration time for each sample was less than $1 \mathrm{~min}$. The filters were preequilibrated with the rinse solution for $3 \mathrm{hr}$ at $4^{\circ} \mathrm{C}$ and, after filtration, counted in a gamma counter.

The ability of cholinergic drugs to inhibit ${ }^{125}$ I-NBT binding to chick retina homogenates was determined by including various concentrations of the ligands in binding assays that also included $1 \mu \mathrm{M}$ BGT. Chlorisondamine was obtained from Ciba-Geigy, $d$-tubocurarine from CalBiochem, benzoquinonium from Sterling Winthrop, cytisine from ICN Pharmaceuticals, and trimethaphan camsylate from Hoffman-La Rochc. Dihydro- $\beta$-crythroidine was a generous gift from Merck, Sharp and Dohme. All other drugs were obtained from Sigma. $\mathrm{IC}_{50}$ values were calculated as the concentration of drug necessary to block $50 \%$ of the specific ${ }^{125}$ I-NBT binding. $K_{I}$ values were calculated as $\mathrm{IC}_{50} /(1+$ [ ${ }^{125}$ [-NBT] $/ K_{d}$ ), assuming a $K_{d}$ of 2 nM for NBT.

Autoradiographic and immunohistochemical procedures. Eyecup preparations from 7-d-old chicks were incubated in oxygenated Tyrode's solution containing $2 \mathrm{mM} \mathrm{CaCl}_{2}, 1 \mathrm{~mm} \mathrm{MgCl}, 1 \mathrm{mg} / \mathrm{ml} \mathrm{BSA}$, and $2 \mathrm{nM}$ ${ }_{125}$ I-NBT, together with any competing ligands. The eyecups were kept at $37^{\circ} \mathrm{C}$ in the dark in a humidified and oxygenated chamber for 45 min. Each eyecup was then washed 3 times for 10 min each with $3 \mathrm{ml}$ oxygenated Tyrode's containing BSA at room temperature and fixed in $2.8 \%$ glutaraldehyde in $0.12 \mathrm{M} \mathrm{NaPO}_{4}$ buffer, $\mathrm{pH} 7.4$. The retina, together with the choroid and pigmented epithelium layers, was removed from each eyecup and the bound radioactivity determined in a gamma counter. After $4 \mathrm{hr}$ in glutaraldehyde at room temperature, the retinas were then washed twice for $10 \mathrm{~min}$ each in $0.12 \mathrm{M} \mathrm{NaPO}_{4}$ buffer at $4^{\circ} \mathrm{C}$ and then postfixed overnight in $1 \% \mathrm{OsO}_{4}$ in phosphate buffer at $4^{\circ} \mathrm{C}$. The tissues were then washed in buffer, dehydrated in increasing ethanol solutions, and then embedded in Epon. Half-micrometer cross-sections of retina were cut on a microtome and mounted on glass slides for autoradiography using Ilford L-4 emulsion. After exposure for 1-2 months, the autoradiograms were developed in Kodak D19 (4 min at room temperature). For the immunochemical localization of choline acetyltransferase activity, a retina from an $8 \mathrm{~d}$ posthatched chick was fixed by immersion in Zamboni's fixative (Zamboni and Demartino, $1967)$ overnight. The retina was immersed in $20 \%$ sucrose in PBS (50 $\mathrm{mm} \mathrm{NaPO}, \mathrm{pH} 7.2 ; 137 \mathrm{~mm} \mathrm{NaCl}$ ) before freezing, and then $10 \mu \mathrm{m}$ cryostat sections were collected on chrome alum-coated slides. The slides were treated for $10 \mathrm{~min}$ in $2.7 \% \mathrm{H}_{2} \mathrm{O}_{2}$ in PBS to reduce endoperoxidase activity, washed, and then incubated overnight in a 1:3000 dilution of rabbit anti-chicken choline acetyltransferase serum (Johnson and Epstein, 1986) in PBS containing 10\% goat serum, $0.3 \%$ Triton $\mathrm{X}-100$, and $0.1 \%$ sodium azide. Controls consisted of sections incubated with a similar dilution of normal rabbit serum. The sections were then stained by the peroxidase-antiperoxidase method of Sternberger (1979).

\section{Results}

\section{NBT antagonism of nicotinic agonist-induced retinal} depolarization

NBT substantially blocks a depolarization activated by the nicotinic agonist DMPP in intact chick retina (Fig. 1). Both $10^{-4}$ $\mathbf{M}$ kainic acid, an excitatory amino acid analog, and $10^{4} \mathrm{M}$ DMPP induce depolarizations in intact retina under control conditions (Fig. $1 A$ ). Hexamethonium $\left(10^{-4} \mathrm{M}\right.$; Fig. $1 B$ ), $d$-tubocurarine, dihydro- $\beta$-erythroidine, or trimethaphan $\left(10^{-4} \mathrm{M}\right.$ each; data not shown) substantially blocks the DMPP-induced depolarizations while having little effect on the kainic acidinduced depolarizations. Ten micromolar 6-cyano-7-nitroquinoxaline-2,3-dione (CNQ X), an antagonist primarily for nonNMDA excitatory amino acid receptors (Honoré et al., 1988), completely blocked the kainic acid response but had no effect on the DMPP-induced depolarization (data not shown). The depolarization induced by DMPP involves a receptor that is sensitive to reduction. Treatment by $10^{-3} \mathrm{M}$ dithiothreitol completely abolishes the DMPP response but not the kainic acid response (Fig. 1D), and the DMPP response is completely restored by reoxidation by $10^{-3} \mathrm{M}$ dithiobisnitrobenzoic acid (Fig. $1 E)$. BGT $\left(10^{-5} \mathrm{M}\right)$ applied for $1 \mathrm{hr}$ had no effect on the DMPP response (Fig. $1 F$ ) but $10^{-7} \mathrm{M}$ NBT substantially blocked the DMPP response ( $>70 \%$ blockade, Fig. $1 G$ ). Unlike the quickly reversible effects of hexamethonium, $d$-tubocurarine, dihydro$\beta$-erythroidine, or trimethaphan, the NBT blockade persisted for up to $17 \mathrm{hr}$ after an initial partial recovery (Fig. $1 \mathrm{H}$, additional data not shown). Similar results were obtained in other experiments. In 3 preparations, 100 nM NBT blocked the DMPP response by $50-90 \%$ with no effect on the kainic acid responses. Thus, these data suggest that NBT antagonizes nicotinic receptors found in chick retina. Furthermore, since synaptic interactions in the retina were substantially blocked by the high$\mathrm{Mg}^{2+}$, low- $\mathrm{Ca}^{2+}$ conditions used in the recording medium, these receptors are presumably located on retinal ganglion cells, whose axons constitute the optic nerve. Interestingly, not all of the nicotinic response in the chick retina is blocked by concentrations of up to $750 \mathrm{nM}$ NBT (data not shown).

\section{${ }^{25} I-N B T$ binding to retinal homogenates}

Previous evidence demonstrated that ${ }^{125}$ I-NBT binds to 2 distinct sites in chick ciliary ganglia: one that is recognized by BGT and another site that is not (Chiappinelli, 1983; Loring et al., 1984; Halvorsen and Berg, 1986; Loring and Zigmond, 1987). To determine if this is also the case in the CNS and specifically in chick retina, the concentration dependence of ${ }^{125}$ I-NBT binding to retinal homogenates was determined in the absence of competing toxins or in the presence of either unlabeled $1 \mu \mathrm{M}$ BGT or $1 \mu \mathrm{M}$ NBT (Fig. 2). BGT blocked a substantial portion of the binding at all concentrations of ${ }^{125}$ I-NBT tested. NBT blocked not only this binding site but also an additional site. Scatchard transformations of the data (e.g., Fig. 2, inset) indicated that the site shared with BGT (binding in the absence of toxins minus binding in the presence of BGT), had, in $3 \mathrm{cx}$ - 

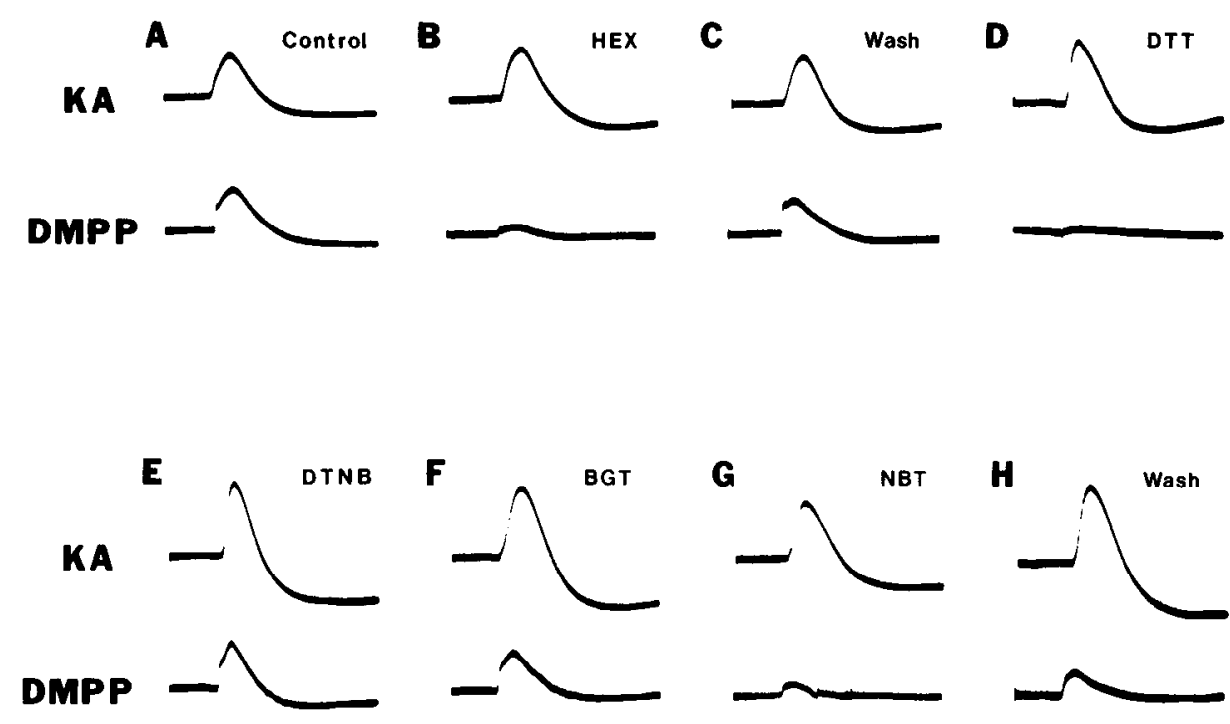

$1 \mathrm{mv} \bigsqcup_{10 \mathrm{sec}}$

Figure 1. Selective blockade of a hexamethonium-sensitive depolarization induced by DMPP in intact chick retina. Recordings from a single eyecup preparation were performed as described in Materials and Methods. $A$, Control responses to DMPP and to the excitatory amino acid analog, kainic acid. Upper trace (KA) represents the response to application of $50 \mu 1$ of $100 \mu \mathrm{M}$ kainic acid, which served as a control response throughout the experiment. Lower trace (DMPP) represents the depolarization after application of $50 \mu \mathrm{l}$ of $100 \mu \mathrm{M}$ DMPP applied 4 min before the kainic acid response. A 4 min recovery period between the application of DMPP and kainic acid was used throughout the experiment. $B$, Responses to kainic acid and DMPP $10 \mathrm{~min}$ after continual perfusion with $100 \mu \mathrm{M}$ hexamethonium. The DMPP response is blocked by at least $90 \%$. $C$, A 15 min washout of hexamethonium led to a substantial recovery of the DMPP response. $D$, Reduction by 1 mM dithiothreitol (DTT) for 20 min completely blocked the DMPP response but had little effect on the kainic acid response. $E$, Oxidation by 1 mM dithiobisnitrobenzoic (DTNB) acid for 5 min followed by a 5 min washout restored the DMPP response. $F, \mathrm{~A} 1 \mathrm{hr}$ treatment with $10 \mu \mathrm{M}$ BGT had little, if any, effect. Five ml of $10 \mu \mathrm{M}$ BGT had been recirculated $1 \mathrm{hr}$. The recording shown was taken $8 \mathrm{~min}$ after washing out the toxin. $G$, One hr in $100 \mathrm{~nm}$ NBT substantially blocked the DMPP response ( $75 \%$ decrease in amplitude). Five $\mathrm{ml}$ of $100 \mathrm{nM} \mathrm{NBT}$ in oxygenated Tyrode's had been recirculated through the eyecup and then washed out for $1 \mathrm{~min}$ prior to making the above recordings. $H$, After $1 \mathrm{hr}$ washout, partial recovery (to only a $50 \%$ decrease from the control amplitude) was observed for the DMPP response. No further recovery in the DMPP response was observed for up to $17 \mathrm{hr}$ (not shown).

\section{Concentration dependence of $125_{1-N B T}$ binding}

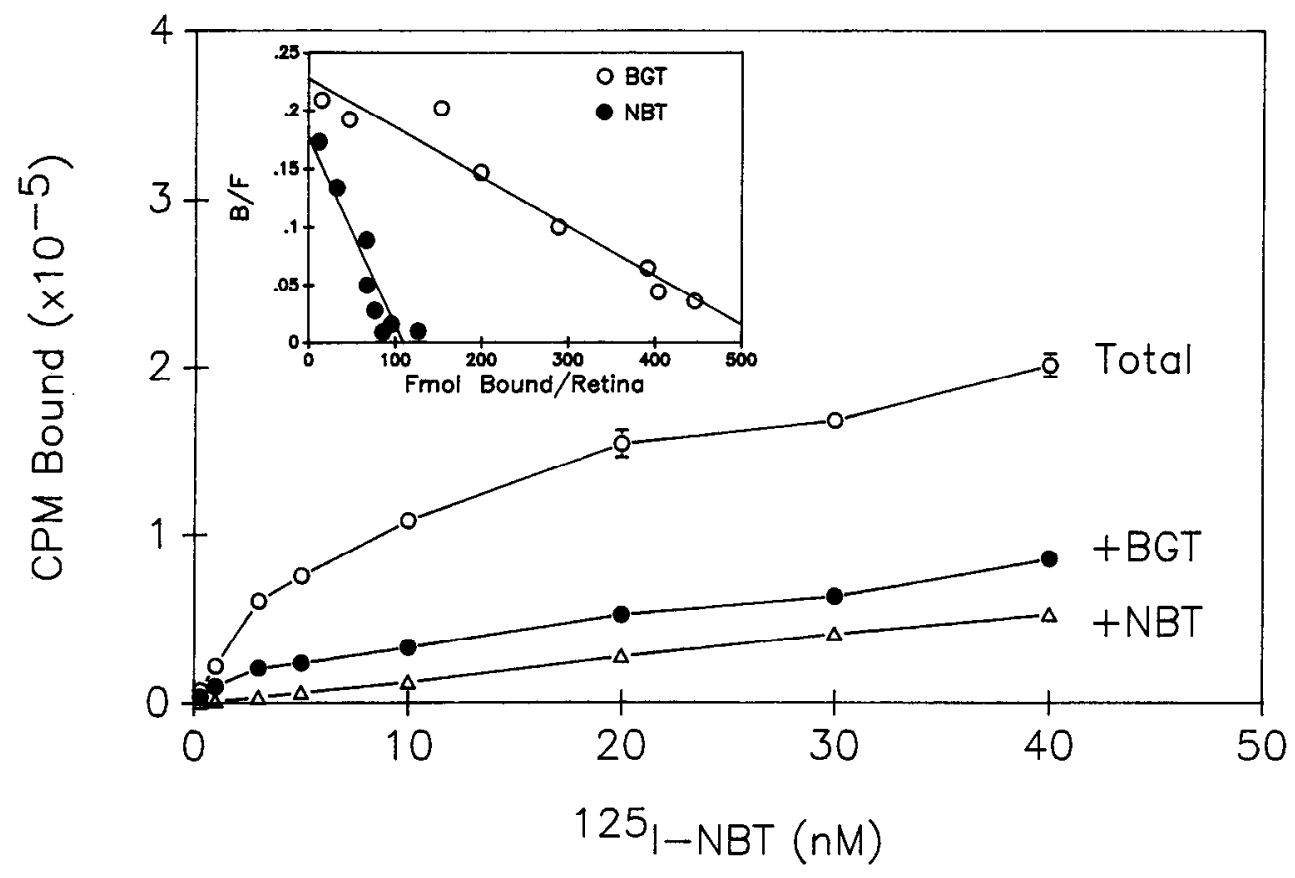

Figure 2. Concentration dependence of ${ }^{125}$ I-NBT binding to homogenates of chick retina. Forty retinas dissected and frozen from chicks $1 \mathrm{~d}$ after hatching were homogenized as outlined in Materials and Methods. Binding of ${ }^{125} \mathrm{I}$ NBT was assessed under 3 conditions: addition of no competing ligands (total, $0)$, addition of $1 \mu \mathrm{M} \mathrm{BGT}(+\mathrm{BGT}, \bullet)$, or addition of $1 \mu \mathrm{M}$ NBT $(+$ NBT, $\triangle)$. Varying concentrations of ${ }^{125}$ I-NBT were added to samples of chick retina (approximately $1 / 3$ retina per sample). After a $4 \mathrm{hr}$ incubation at room temperature, the bound and unbound toxin was separated by centrifugation (see Materials and Methods). Each point represents the mean \pm SD of ${ }^{125}$ I-NBI bound to quadruplicate samples. Inset, A Scatchard transformation of the data. The site shared with BGT $(0)$ was determined by subtracting, for each concentration of ${ }^{125}$ I-NBT, the binding in the presence of $1 \mu \mathrm{M}$ BGT from the binding in the absence of competing ligands. The NBT-specific site $(\bullet)$ was similarly determined by subtracting binding in the presence of $1 \mu \mathrm{M}$ NBT from binding in the presence of $1 \mu \mathrm{M}$ BGT. 


\section{Rate of $125_{1-N B T}$ binding}

Figure 3. Association rate of ${ }^{125}$ I-NBT to homogenates of chick retina. Retinas from 2-d-old chicks were homogenized as outlined in Materials and Methods. Two scts of binding conditions were used: One set of tubes was preincubated $30 \mathrm{~min}$ in $1 \mu \mathrm{M} \mathrm{BGT}$, and the other set was preincubated in $1 \mu \mathrm{M}$ NBT. At lime $0,{ }^{125}$ I-NBT was added to a final concentration of $10 \mathrm{nM}$, and aliquots of homogenates in quadruplicate were assayed at the indicated time. The specific binding was determined as (binding ${ }_{\mathrm{BCT}}$ - binding $\left._{\mathrm{NBT}}\right) \pm\left(\mathrm{SD}_{\mathrm{BGT}}^{2}+\mathrm{SD}_{\mathrm{NBT}}^{2}\right)^{1 / 2}$ and is shown as the open circles. Inset, A linearized transformation of the data and the solid line is a best-fit estimate that corresponds to a $K_{\text {obs }}$ of 0.0311 $\min ^{-1}$. $B_{e}$ represents the amount of binding at equilibrium ( $3 \mathrm{hr}$ ) and $B$ is the binding at other times. Two repetitions of this experiment gave virtually identical values. The curve in the graph of cpm versus time is a transformation of the best-fit estimate except at time 0 , where the curve was forced through $0 \mathrm{cpm}$ bound.

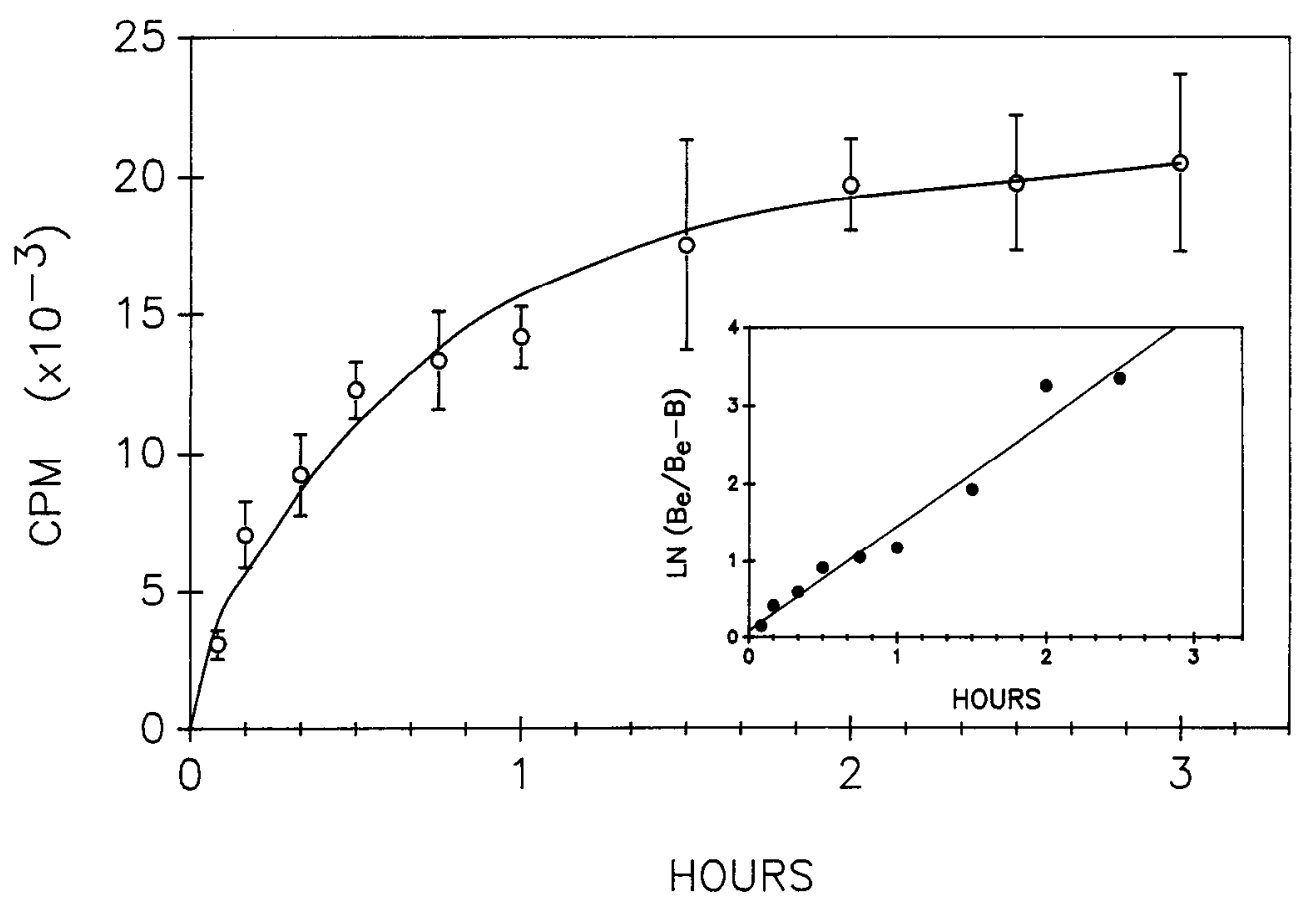

periments, a $K_{d}$ with a range of 5.0-7.0 nM and a $B_{\max }$ of 250$650 \mathrm{fmol}$ bound/retina in 1- to 7-d-old chicks. The NBT-specific site (binding in the presence of BGT minus binding in the presence of unlabeled NBT) had a $K_{d}$ with a range of 1.9-3.0 nM and a $B_{\max }$ of $80-120 \mathrm{fmol} /$ retina.

Since BGT does not block nicotinic function in the chick retina (as measured by the electrophysiological recording scheme used in this paper) or in patch-clamp recordings of isolated ganglion cells from rat retina (Lipton et al., 1987), we concentrated our efforts on the NBT-specific binding site as the site most likely to represent binding to functional nicotinic receptors. ${ }^{125} \mathrm{I}$-NBT binds to this site with a single apparent on-rate $\left(K_{\text {obs }}\right)$ of $0.0311 \mathrm{~min}^{-1}$ (Fig. 3). The dissociation of ${ }^{125}$ I-NBT from this site is more complex (Fig. 4), consisting of an initial rapidly dissociating component and a slower component with an estimated $t_{1 / 2}$ of dissociation of 10.5-25 $\mathrm{hr}(n=4)$. The experiment shown in Figure 4 using a filtration assay suggests that the rapidly dissociating component may represent $60 \%$ of the total binding and that the centrifugation assay may underestimate the portion of ${ }^{125}$ I-NBT binding that rapidly dissociates by $30 \%$.

${ }^{125}$ I-NBT binding to chick retina homogenates in the presence of $1 \mu \mathrm{M}$ BGT is displaceable by a variety of nicotinic agents (Fig. 5, Table 1). The most potent inhibitor of ${ }^{125}$ I-NBT binding was unlabeled NBT $\left(\mathrm{IC}_{50}=3 \times 10^{-9} \mathrm{M}\right)$, followed by agonists such as lobeline $\left(\mathrm{IC}_{50}=3.6 \times 10^{-8} \mathrm{M}\right)$, L-nicotine $\left(\mathrm{IC}_{50}=6.3\right.$ $\left.\times 10^{-7} \mathrm{M}\right)$, and cytisine $\left(\mathrm{IC}_{50}=7.9 \times 10^{-7} \mathrm{M}\right)$. The $\mathrm{IC}_{50}$ 's and calculated $K_{I}$ values for these and several other drugs are found in Table 1. Certain nicotinic antagonists thought to be, in part, channel blockers (Ascher et al., 1979), such as mecamylamine, hexamethonium, and pempidine, failed to block $50 \%$ of the specific NBT binding at concentrations as high as $10^{-3} \mathrm{M}$. In addition, BGT fails to block ${ }^{125}$ I-NBT binding further at $10^{-5}$
M. Furthermore, it should be noted that none of the ligands tested besides unlabeled NBT block ${ }^{125}$ I-NBT binding by more than $80-90 \%$. For instance, no greater blocking effect of lobeline is observed at concentrations greater than $10^{-6} \mathrm{M}$ (Fig. 5), even though a significant amount of NBT binding, approximately $20 \%$, remains. These data suggest that a fraction (10-20\%) of the NBT-specific sitc may not represent nicotinic receptors.

\section{Developmental changes in ${ }^{125} I-N B T$ and ${ }^{125} I-B G T$ binding in chick retina}

Developmental changes in levels of both ${ }^{125}$ I-NBT and ${ }^{125}$ I-BGT binding in the chick retina were also investigated by examining binding in retinas from embryonic day 8 through day 4 posthatch chicks (Table 2). The ${ }^{125} \mathrm{I}-\mathrm{NBT}$ site displaced by NBT but not by BGT was undetectable at $8 \mathrm{~d}$ of embryological development and increased to about $10 \mathrm{fmol} / \mathrm{mg}$ protein at $4 \mathrm{~d}$ after hatching. A similar developmental time course was seen for ${ }^{125} \mathrm{I}$ BGT binding.

Interestingly, these experiments revealed that the ${ }^{125} \mathrm{I}-\mathrm{NBT}$ binding displaced by BGT represents less than $10 \%$ of the total BGT site determined using ${ }^{125} \mathrm{I}-\mathrm{BGT}$ at all ages tested. These data suggest that there are at least 3 toxin binding sites in the chick retina: The NBT-specific binding site, the site NBT shares with BGT, and a site recognized only by BGT. An alternative explanation of the data is that $1 \mu \mathrm{M}$ NBT is not a sufficient concentration to occupy all of the BGT sites, but this seems unlikely since the $K_{d}$ of ${ }^{125}$ I-NBT binding to the site shared with BGT is $5-7 \mathrm{nM}$ (Fig. 2). The nature and function of both the BGT selective binding site and the shared site remain to be determined. Recently, Wolf et al. (1988) have reported that NBT binds with variable affinities to multiple subtypes of BGT binding sites found in chick optic tectum. However, in the optic 




Figure 4. Dissociation of ${ }^{125}$ I-NBT from homogenates of chick retina. Retinas from 2-d-old chicks, homogenized as outlined in Materials and Methods, were preincubated with $10 \mathrm{nM}^{125} \mathrm{I}-\mathrm{NBT}$ at room temperature under 1 of 2 conditions: One group $(A)$ was incubated with $1 \mu \mathrm{M} \mathrm{BGT}$, the other $(B)$ with $1 \mu \mathrm{M}$ NBT. After preincubating for $2 \mathrm{hr}$, the experiment was begun by adding sufficient NBT to group $A$ to equalize the final NBT concentration in both groups. Aliquots $(100 \mu l)$ in quadruplicate from each sample were removed at the indicated times and the remaining ${ }^{125}$ I-NBT bound was determined by the filtration assay. Specific NBT binding was determined as (binding ${ }_{A}-$ binding $\left._{B}\right) \pm\left(\mathrm{SEM}_{A}^{2}\right.$ $\left.+\mathrm{SEM}_{\mathrm{B}}^{2}\right)^{1 / 2}$. The graph plots the specific binding as a percentage of the binding observed at time 0 as a function of elapsed time. The straight portion of the line is a best-fit through the data starting at time $1.5 \mathrm{hr}$ and corresponds to a time 0 intercept of $36 \%$. In 3 experiments using the centrifugation assay, the percentage of binding sites that were slowly dissociating was $68 \pm 21 \%$. Thus, the centrifugation assay may underestimate the portion of rapidly dissociating toxin by as much as $30 \%$.

Table 1. IC $\mathrm{C}_{50}$ and $K_{I}$ of ligands at the NBT site

\begin{tabular}{lll} 
Ligand & $\begin{array}{l}\mathrm{IC}_{50} \\
(\mathrm{M})\end{array}$ & $\begin{array}{l}K_{I} \\
(\mathrm{M})\end{array}$ \\
\hline NBT & $5.0 \times 10^{-9}$ & $3.3 \times 10^{-9}$ \\
Lobeline & $3.6 \times 10^{-8}$ & $2.4 \times 10^{-8}$ \\
Nicotine & $6.3 \times 10^{-7}$ & $4.2 \times 10^{-7}$ \\
Cytisine & $7.9 \times 10^{-7}$ & $5.3 \times 10^{-7}$ \\
DMPP & $1.0 \times 10^{-6}$ & $6.8 \times 10^{-7}$ \\
Dihydro- $\beta$-erythroidine & $1.6 \times 10^{-6}$ & $1.1 \times 10^{-6}$ \\
Trimethaphan camsylate & $6.3 \times 10^{-6}$ & $4.2 \times 10^{-6}$ \\
ACh & $1.6 \times 10^{-5}$ & $1.0 \times 10^{-5}$ \\
$d$-Tubocurarine & $2.0 \times 10^{-5}$ & $1.3 \times 10^{-5}$ \\
Carbamylcholine & $2.8 \times 10^{-5}$ & $1.9 \times 10^{-5}$ \\
Atropine sulfate & $1.4 \times 10^{-4}$ & $9.3 \times 10^{-5}$ \\
Benzoquinonium & $1.8 \times 10^{-4}$ & $1.2 \times 10^{-4}$ \\
Decamethonium & $1.8 \times 10^{-4}$ & $1.2 \times 10^{-4}$ \\
Eserine sulfate & $2.6 \times 10^{-4}$ & $1.7 \times 10^{-4}$ \\
Gallamine triethiodide & $2.6 \times 10^{-4}$ & $1.7 \times 10^{-4}$ \\
Chlorisondamine & $2.8 \times 10^{-4}$ & $1.9 \times 10^{-4}$ \\
Mecamylamine & $>10^{-3}$ & - \\
Hexamethonium & $>10^{-3}$ & - \\
Pempidine & $>10^{-3}$ & - \\
BGT & $>10^{-5}$ & - \\
\hline
\end{tabular}

${ }^{a}$ Determined in the presence of $10^{-6} \mathrm{M}$ eserine sulfate.

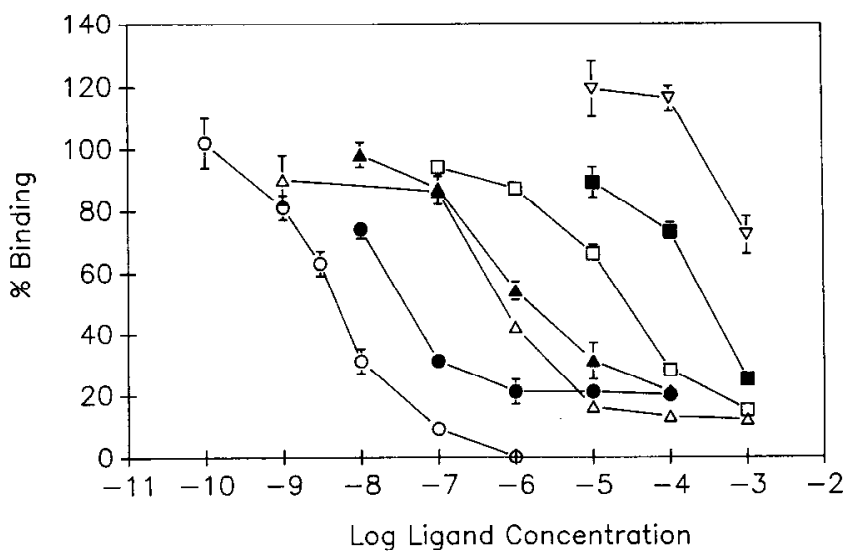

Figure 5. Displacement of ${ }^{125}$ I-NBT binding by representative nicotinic ligands. To determine the $\mathrm{IC}_{50}$ values of various drugs, homogenates of chick retinas of various ages (1-7 d) were added to homogenization buffer containing ${ }^{125} \mathrm{I}-\mathrm{NBT}$ and competing ligands to give a final concentration of $2 \mathrm{nM}{ }^{125} \mathrm{I}-\mathrm{NBT}, 1 \mu \mathrm{M}$ BGT, and the various appropriate concentrations of drugs. Quadruplicate samples were incubated for $2 \mathrm{hr}$ at room temperature and then assayed using the centrifugation assay. Specific binding was determined by subtracting nonspecific binding observed in the presence of $1 \mu \mathrm{M}$ NBT. Maximum binding was determined as binding in the presence of $1 \mu \mathrm{M}$ BGT minus nonspecific binding. The graph plots the percentage of binding observed (binding in presence of drug/maximum binding $\times 100 \%$ ) as a function of drug concentration. The drugs used in these experiments were as follows: $O$, NBT; $\theta$, lobeline; $\triangle$, nicotine; $\boldsymbol{\Delta}$, DHBE; $\square$, carbamylcholine; $\boldsymbol{\square}$, chlorisondamine; $\nabla$, hexamethonium.

tectum, no evidence was found for a ${ }^{125}$ I-NBT-selective binding site.

\section{Localization of ${ }^{125}$ I-NBT binding compared to cholinergic innervation in the chick retina}

All of the above binding experiments were done on homogenized chick retinas. In order to localize ${ }^{125}$ I-NBT binding at the light microscopic level, intact retina from $7 \mathrm{~d}$ chicks were incubated in $2 \mathrm{nM}^{125} \mathrm{I}-\mathrm{NBT}$ in the presence of various competing ligands. The retinas were sectioned and used for the autoradio-

Table 2. Developmental regulation of toxin binding to chick retina

\begin{tabular}{|c|c|c|c|}
\hline Age (d) & $\begin{array}{l}{ }^{125} \mathrm{I}-\mathrm{NBT} \\
\text { binding } \\
\text { (fmol/mg } \\
\text { protein) }\end{array}$ & $\begin{array}{l}\text { Shared } \\
{ }^{125} \text { I-NBT } \\
\text { binding } \\
\text { (fmol/mg } \\
\text { protein) }\end{array}$ & $\begin{array}{l}{ }^{125} \text { I-BGT } \\
\text { binding } \\
\text { (fmol/mg } \\
\text { protein) }\end{array}$ \\
\hline Embryonic 8 & N.D. ${ }^{d}$ & N.D. & N.D. \\
\hline Embryonic 12 & $2.2 \pm 1.0$ & $7.4 \pm 2.9$ & $81 \pm 9$ \\
\hline Embryonic 14 & $2.6 \pm 2.6$ & $10.3 \pm 3.8$ & $142 \pm 6$ \\
\hline Embryonic 18 & $6.1 \pm 3.7$ & $17.01 \pm 4.6$ & $205 \pm 27$ \\
\hline Posthatch 1 & $9.2 \pm 4.5$ & $75.3 \pm 5.6$ & $673 \pm 39$ \\
\hline Posthatch 4 & $10.8 \pm 3.6$ & $42.9 \pm 4.0$ & $511 \pm 38$ \\
\hline
\end{tabular}

Quadruplicate samples consisting of approximately $1 / 3$ of a retina were incubated in the presence of either $10 \mathrm{nM}{ }^{125} \mathrm{I}-\mathrm{NBT}$ or ${ }^{125} \mathrm{I}-\mathrm{BGT}$ plus any competing ligands (see below) for $2 \mathrm{hr}$ at room temperature. Unbound toxin was removed using the centrifugation assay. Protein concentrations were determined using the bicinchoninic acid protein assay (Pierce Chemical).

${ }^{a}$ Specific ${ }^{125}$ I-NBT binding displaced by $1 \mu \mathrm{M}$ NBT in the presence of $1 \mu \mathrm{MBGT}$.

${ }^{b}$ Specific ${ }^{125}$ I-NBT binding displaced by $1 \mu \mathrm{M}$ BGT.

- Specific ${ }^{125}$ I-BGT binding displaced by $1 \mu \mathrm{M}$ BGT.

${ }^{d}$ N.D., no detectable specific binding was observed. 


\section{BG T}

\section{DHBE}

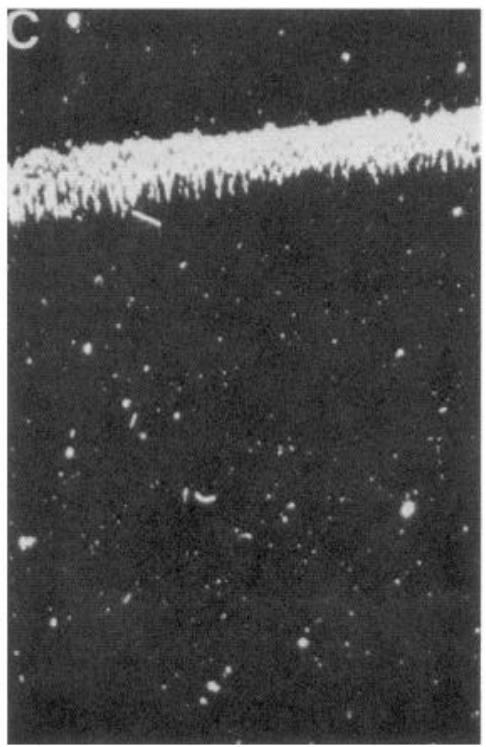



\section{Anti-ChAT}

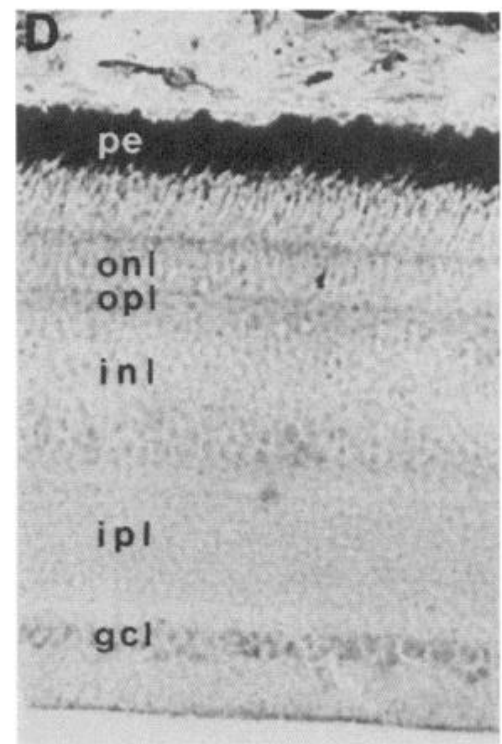

\section{N R S}

Figure 6. Localization of ${ }^{125}$ I-NBT binding in chick retina compared with the localization of choline acetyltransferase-like immunoreactivity. $A$ $(B G T)$, A light microscopic autoradiogram in dark-field mode from a retina incubated in $1 \mu \mathrm{M}$ BGT. The pigmented epithelium appears as the white band at the top, while the silver grains appear as white dots. Exposure time, 2 months. $B$ (Anti-ChAT), The histochemical localization of choline acetyltransferase-like immunoreactivity in a $10 \mu \mathrm{m}$ section of chick retina. Staining is observed in cell bodies in both the ganglion cell layer and the inner side of the inner nuclear layer. Staining in neural processes is also observed in 2 layers of the inner plexiform layer that correspond closely with the 2 layers of bound ${ }^{125} \mathrm{I}$-NBT observed in the top-left panel. $C(D H B E)$, A dark-field autoradiogram from a retina incubated in $1 \mu \mathrm{M}$ BGT plus $100 \mu \mathrm{M}$ dihydro- $\beta$-erythroidine. Dihydro- $\beta$-erythroidine blocks the specific ${ }^{125}$ I-NBT binding in the inner plexiform layer. Exposure time, 2 months. $D(N R S)$, No immunohistochemical staining is observed if normal rabbit serum is substituted for the rabbit antiserum to chicken choline acetyltransferase. Abbreviations: pe, pigmented epithelium; onl, outer nuclear layer; opl, outer plexiform layer; inl, inner nuclear layer; ipl, inner plexiform layer; $g c l$, ganglion cell layer.

graphic study shown in Figure $6(A, C)$. In the absence of competing ligands, grains were observed over the same regions described for ${ }^{125}$ I-BGT binding in chick retina (Vogel and Nirenberg, 1976); that is, in a narrow band in the outer plexiform layer and as a broad, diffuse band over the inner plexiform layer (data not shown). In the presence of $1 \mu \mathrm{M}$ BGT to prevent binding to the shared site, the specific NBT binding is restricted to 2 bands in the inner plexiform layer (Fig. 6A). These bands correspond very closely to 2 bands of choline acetyltransferase immunoreactivity (Fig. $6 \mathrm{~B}$ ). The binding of ${ }^{125} \mathrm{I}-\mathrm{NBT}$ is eliminated in the inner plexiform layer by $1 \mu \mathrm{M}$ unlabeled NBT (not shown) or by $100 \mu \mathrm{M}$ dihydro- $\beta$-erythroidine plus $1 \mu \mathrm{M}$ BGT (Fig. $6 C$ ). These data suggest that nicotinic receptors recognized by ${ }^{125} \mathrm{I}-$ NBT are located in regions of the chick retina in which $\mathrm{ACh}$ is synthesized and, perhaps, released as a neurotransmitter.

\section{Discussion}

Physiological effects of snake venom neurotoxins

Nicotinic ACh receptors are thought to play important roles in processing retinal signals in a variety of organisms (reviewed by Neal, 1983; Puro, 1985). Electrophysiological evidence implicates nicotinic transmission onto retinal ganglion cells in the 
rabbit (Masland and Ames, 1976; Ariel and Daw, 1982a, b) and cat retina (Ikeda and Sheardown, 1982). Recently, we have demonstrated that isolated ganglion cells from rat retina possess nicotinic receptors and that these receptors are blocked by NBT but not by BGT (Lipton et al., 1987).

Although relatively few clectrophysiological studies have been performed on chick retina, several lines of evidence suggest that cholinergic function is important in this retina as well. The inner plexiform layer of the chick retina contains high-affinity choline uptake sites (Baughman and Bader, 1977) and stains for both acetylcholinesterase activity and choline acetyltransferase-like immunoreactivity (Millar et al., 1985; Spira et al., 1987). Muscarinic receptors are similarly localized to this region of the chick retina (Sugiyama et al., 1977), as are some of the BGT binding sites (Vogel and Nirenberg, 1976; Vogel et al., 1977). Although BGT binding has been used as a marker for nicotinic receptors in avian retina (Vogel and Nirenberg, 1976; Wang and Schmidt, 1976; Vogel et al., 1977; Yazulla and Schmidt, 1977), several lines of evidence suggest that BGT fails to recognize most forms of neuronal nicotinic receptors. BGT fails to block nicotinic function in most vertebrate autonomic ganglia (reviewed by Chiappinelli, 1985), and in addition, this toxin has no effect on nicotinic receptors found on central neurons in the spinal cord (Duggan et al., 1976), interpeduncular nucleus (Brown et al., 1983), locus coeruleus (Egan and North, 1986), and isolated ganglion cells from rat retina (Lipton et al., 1987). BGT also does not recognize putative neuronal nicotinic receptors that have been isolated from the brains of chickens (Whiting and Lindstrom, 1986a, b) and rats (Whiting and Lindstrom, 1987) using monoclonal antibodies raised against nicotinic receptors. In the present study, $10 \mu \mathrm{M}$ BGT failed to block the hexamethonium-sensitive depolarization in chick retina induced by the application of DMPP.

Unlike BGT, NBT blocks nicotinic receptor function in a variety of neuronal preparations including the chick ciliary ganglion (Ravdin and Berg, 1979; Chiappinelli, 1983; Loring et al., 1984), rat superior cervical ganglion (Chiappinelli and Dryer, 1984; Sah et al., 1987), chick sympathetic ganglia (Chiappinelli and Dryer, 1984), and isolated rat retinal ganglion cells (Lipton et al., 1987). Recently, 2 "neuronal" type nicotinic receptors have been expressed in frog oocytes, following injection of mRNA derived from cDNA clones encoding putative nicotinic receptor subunits from rat brain and from a rat pheochromocytoma cell line (Boulter et al., 1987). Both of these receptors are blocked by NBT but not by BGT. Similar genes encoding putative subunits for chick neuronal nicotinic receptors have also been reported recently (Nef et al., 1988; Schoepfer et al., 1988), but the functional expression and pharmacological properties of these chick receptors have not yet been published.

We find that $100 \mathrm{~nm}$ NBT substantially blocks nicotinic function on ganglion cells in the intact chick retina. However, since NBT does not bluck all of the nicotinic function, the possibility remains that NBT fails to recognize certain subtypes of nicotinic receptors present in this tissue. Alternatively, diffusion barriers may prevent NBT from reaching all nicotinic receptors in the intact chick retina. Interestingly, a certain combination of subunit mRNAs encoding neuronal nicotinic receptors from rat has recently been described that, when injected into frog oocytes, give rise to the only neuronal nicotinic receptor subtype yet described that is both functional and insensitive to NBT (Wada et al., 1988).

All known nicotinic receptors have a vicinal disulfide bond present on the $\mathrm{ACh}$ binding subunit that is extremely sensitive to reduction (e.g., Kao et al., 1984). In fact, the presence or absence of the 2 adjacent cysteine residues has been the main strategy for distinguishing $\alpha$-subunit DNA sequences from those of other neuronal nicotinic receptor subunits (e.g., Nef et al., 1988; Wada ct al., 1988). Since all of the functional nicotinic response measured in chick retina is blocked by dithiothreitol, retinal receptors, whether or not they are blocked by NBT, clearly have a similar susceptibility to reduction.

\section{${ }^{125} I-N B T$ binding to chick retina}

${ }^{125}$ I-NBT binds to the NBT-specific site with a single apparent affinity $\left(K_{d}=2-3 \mathrm{~nm}\right.$; Fig. 2) and a single on-rate (Fig. 3) but dissociates in a biphasic manner (Fig. 4). These data are highly reminiscent of the binding data of ${ }^{125}$ I-NBT to cultured neurons from the chick ciliary ganglion (Halvorsen and Berg, 1986), in which 2 dissociation rates were observed and the proportion of ${ }^{125}$ I-NBT binding that dissociates slowly was observed to increase with incubation time or with higher concentrations of ${ }^{125}$ I-NBT. A similar 2-phase dissociation of NBT, in which the proportion of slowly dissociating toxin was dependent on incubation time and toxin concentration, was demonstrated by electrophysiological means in cultures of neurons from the rat SCG (Sah et al., 1987). Thus, a biphasic dissociation appears to be a common feature of NBT binding, although the slow dissociation rate we observed in homogenates of chick retina represents the slowest rate of dissociation of NBT yet observed in a neuronal preparation. This fact, coupled with 30 - to 100 fold greater yield of binding sites per tissue compared with that obtained from the chick ciliary ganglion (e.g., Loring and Zigmond, 1987) makes the retina an attractive source for the biochemical characterization of neuronal nicotinic receptors.

The pharmacological profile of ${ }^{125}$ I-NBT binding to chick retina appears to be closer to that of the chick ciliary ganglion (Halvorsen and Berg, 1986) than to that of ${ }^{3} \mathrm{H}$-nicotine binding to immunopurified sites from chick brain (Whiting and Lindstrom, 1986b). In fact, the only major difference between the NBT binding site in the chick retina as opposed to that in the ciliary ganglion is that $\mathrm{ACh}$ is a 40 -fold less potent inhibitor of NBT binding in the retina (Table 1; Halvorsen and Berg, 1986). Like the ${ }^{3} \mathrm{H}$-nicotine binding in chick brain, ${ }^{125} \mathrm{I}-\mathrm{NBT}$ binding in chick retina is not displaced by certain nicotinic antagonists such as mecamylamine and hexamethonium, which are believed to function as channel blockers (Ascher et al., 1979). (Likewise, ncither mecamylamine nor hexamethonium displace ${ }^{125}$ I-NBT from chick ciliary ganglion; $R$. Loring, unpublished observations). Another antagonist, $d$-tubocurarine, is approximately equipotent at displacing ${ }^{3} \mathrm{H}$-nicotine binding in chick brain or ${ }^{125}$ I-NBT binding to either chick ciliary ganglion or retina. However, agonists are generally 2 orders of magnitude more potent in displacing ${ }^{3} \mathrm{H}$-nicotine binding (Whiting and Lindstrom, 1986b) than in displacing ${ }^{125}$ I-NBT binding from either the chick ciliary ganglion or retina. One explanation put forward for this difference is that the high-affinity ${ }^{3} \mathrm{H}$-nicotine binding to brain sites represents binding to a desensitized receptor (Whiting and Lindstrom, 1986b).

It should be noted that the portion of ${ }^{125}$ I-NBT binding displaced by nicotinic ligands has been treated as a homogeneous receptor population in the present study. In fact, as already noted, heterogeneity in putative nicotinic receptors has been uncovered in the CNS by both molecular biology (Boulter et al., 1987; Wada et al., 1988) and immunological techniques 
(Whiting et al., 1987). However, ${ }^{3} \mathrm{H}$-nicotine binding to $2 \mathrm{im}$ munologically purified subtypes of putative receptors from chick brain has virtually identical pharmacological profiles, suggesting that the binding of nicotinic ligands may not differ much in receptor subtypes with high affinity for nicotine (Whiting et al., 1987). In contrast, NBT blocks functional nicotinic receptors in both the chick ciliary ganglion (e.g., Ravdin and Berg, 1979) and the chick retina (present paper), and in both of these preparations, relatively high concentrations of nicotine are required to displace ${ }^{125}$ I-NBT (Halvorsen and Berg, 1986; this paper). This difference in nicotine displacement of ${ }^{125} \mathrm{I}-\mathrm{NBT}$ binding in ciliary ganglion versus ${ }^{3} \mathrm{H}$-nicotine binding in chick brain has prompted the suggestion that brain and ganglionic receptors are pharmacologically distinct receptor subtypes with demonstrable differences in agonist affinity (Whiting and Lindstrom, 1986b). Thus, the ciliary ganglionic receptors are proposed to have low affinity for agonists. In fact, electrophysiological studies of nicotinic receptors on cultured chick ciliary neurons suggest that these receptors indeed have a relatively low affinity for $\mathrm{ACh}$ (Ogden et al., 1984). High-affinity nicotine and $\mathrm{ACh}$ binding in the brains of several species have now been extensively studied (reviewed by Lindstrom et al., 1987), but little electrophysiological evidence is yet available to indicate whether functional nicotinic receptors from CNS have high affinities for agonists. In at least one part of the CNS, the chick retina, our data suggest that the class of functional nicotinic receptors blocked by NBT has low affinity for agonists. However, our data also indicate that NBT may not block all types of functional nicotinic receptors present in chick retina. It is of interest to establish whether the nicotinic receptors present in chick retina that are not blocked by NBT have high affinity for ${ }^{3} \mathrm{H}$-nicotine.

The localization of specific ${ }^{125}$ I-NBT binding in the chick retina is very similar to that of the muscarinic antagonist ${ }^{3} \mathrm{H}$ quinuclidinyl benzilate (Sugiyama et al., 1977) and to the distribution of nerve terminals containing choline acetyltransferase-like immunoreactivity (Millar et al., 1985; Spira et al., 1987). In addition, the monoclonal antibodies used to immunopurify putative neuronal nicotinic receptors from chick brain have recently been used to label putative cholinoceptive neurons in the chick retina (Keyser et al., 1988). These antibodies label 2 subtypes of ganglion cells in the retina as well as one amacrine cell subtype. These putative cholinoceptive cells project to the same laminae of the inner plexiform layer as those innervated by choline acetyltransferase-like immunoreactive amacrine cells. In addition, double-labeling experiments indicate that few, if any, of the cholinoceptive neurons in chick retina also stain for choline acetyltransferase-like activity. The pattern of binding by ${ }^{125}$ I-NBT observed in this study is indistinguishable from the antibody staining patterns within the inner plexiform layer observed by Keyser et al. Further work is necessary to establish whether the antibodies recognize the same macromolecular entity as does NBI in the chick retina.

In summary, our data suggests that NBT blocks at least some types of nicotinic receptors found on ganglion cclls in the chick retina, that the pharmacology of ${ }^{125}$ I-NBT binding to chick retina is nicotinic in nature, and that ${ }^{125}$ I-NBT binding is localized to those regions of the chick retina where nicotinic synaptic transmission would be expected.

\section{References}

Ariel, M., and N. W. Daw (1982a) Effects of cholinergic drugs on receptive field properties of rabbit retinal ganglion cells. J. Physiol. (Lond.) 324: 135-160.
Ariel, M., and N. W. Daw (1982b) Pharmacological analysis of directionally-sensitive rabbit retinal ganglion cells. J. Physiol. (Lond.) 324: 161-185.

Ascher, P., W. A. Large, and H. P. Rang (1979) Studies on the mechanism of action of acetylcholine antagonists on rat parasympathetic ganglion cells. J. Physiol. (Lond.) 295: 139-170.

Baughman, R. W., and C. R. Bader (1977) Biochemical characterization and cellular localization of the cholinergic system in the chicken retina. Brain Res. 138: 469-485.

Boulter, J., J. Connally, E. Deneris, D. Goldman, S. Heinemann, and J. Patrick (1987) Functional expression of two neuronal nicotinic receptors from c-DNA clones identifies a gene family. Proc. Natl. Acad. Sci. USA 84: 7763-7767.

Brown, D. A., R. J. Docherty, and J. V. Halliwell (1983) Chemical transmission in the rat interpeduncular nucleus in vitro. J. Physiol. (Lond.) 353: 101-109.

Chiappinelli, V. A. (1983) Kappa-bungarotoxin: A probe for the neuronal nicotinic acetylcholine receptor in the avian ciliary ganglion. Brain Res. 277: 9-22.

Chiappinelli, V. A. (1985) Actions of snake venom toxins on neuronal nicotinic receptors and other neuronal receptors. Pharmacol. Ther. 31: $1-32$.

Chiappinelli, V. A., and S. Dryer (1984) Nicotinic transmission in sympathetic ganglia: Blockade by the snake venom neurotoxin kappabungarotoxin. Neurosci. Lett. 50: 239-244.

Chiappinelli, V. A., and R. E. Zigmond (1978) $\gamma$-Bungarotoxin blocks nicotine transmission in the avian ciliary ganglion. Proc. Natl. Acad. Sci. USA 75: 2999-3003.

Duggan, A. W., J. G. Hall, and C. Y. Lee (1976) Alpha-bungarotoxin, cobra toxin and excitation of Renshaw cells by acetylcholine. Brain Res. 107: 166-170.

Egan, T. M., and R. A. North (1986) Actions of acetylcholine and nicotine on rat locus coeruleus neurons in vitro. Neuroscience 19 . $565-571$.

Halvorsen, S. W., and D. K. Bcrg (1986) Identification of a nicotinic acetylcholine receptor on neurons using an $\alpha$-neurotoxin that blocks receptor function. J. Neurosci. 6: 3405-3412.

Honoré, T., S. N. Davis, J. Drejer, E. J. Fletcher, P. Jacobsen, D. Lodge, and F. E. Nielsen (1988) Quinoxalenediones: Potent competitive non-NMDA glutamate receptor antagonists. Science 241: 701-703.

Ikeda, M., and M. J. Sheardown (1982) Acetylcholine may be an excitatory transmitter mediating visual excitation of "transient" cells with the periphery effect in the cat retina: Iontophoretic studies in vivo. Neuroscience 7: 1299-1308.

Johnson, C. D., and M. L. Epstein (1986) Monoclonal antibodies and polyvalent antiserum to chick choline acetyltransferase. J. Neurochem. 46: 968-976.

Kao, P. N., A. J. Dwork, R. J. Kalodny, M. L. Silver, J. Wideman, S. Stein, and A. Karlin (1984) Identification of the $\alpha$-subunit halfcystine specifically labeled by an affinity reagent for the acetylcholine receptor binding site. J. Biol. Chem. 259: 11662-11665.

Keyser, K. T., T. E. Hughes, P. J. Whiting, J. M. Lindstrom, and H. J. Karten (1988) Cholinoceptive neurons in the retina of the chick: An immunohistochemical study of the nicotinic acetylcholine receptors. Visual Neurosci. 1: 349-366.

Lindstrom, J., R. Schoepfer, and P. Whiting (1987) Molecular studies of the neuronal nicotinic acetylcholine receptor family. Mol. Neurobiol. 1: 281-337.

Lipton, S. A., E. Aizenman, and R. H. Loring (1987) Neural nicotinic acetylcholine responses in solitary mammalian retinal ganglion cells. Pfluegers Arch. 410: 37-43.

Lipton, S. A., M. P. Frosch, M. D. Phillips, D. L. Tauck, and E. Aizenman (1988) Nicotinic antagonists cnhance process outgrowth by rat retinal ganglion cells in culture. Science 239: 1293-1296.

Loring, R. H. (1985) A method for recording agonist-induced depolarizations in small autonomic ganglia. J. Neurosci. Methods $12: 241-$ 248.

Loring, R. H., and R. E. Zigmond (1987) Ultrastructural distribution of ${ }^{125}$ I-toxin $F$ binding sites on chick ciliary neurons: Synaptic localization of a toxin that blocks ganglionic nicotinic receptors. J. Neurosci. 7: 2153-2162.

Loring, R. H., V. A. Chiappinelli, R. E. Zigmond, and J. B. Cohen (1984) Characterization of a snake venom neurotoxin which blocks nicotinic transmission in the avian ciliary ganglion. Neuroscience 11 : 989-999.

Loring, R. H., D. Andrews, W. Lane, and R. E. Zigmond (1986) Amino 
acid sequence of toxin $F$, a snake venom that blocks neuronal nicotinic receptors. Brain Res. 36: 30-37.

Masland, R. H., and A. Ames, III (1976) Responses to acetylcholine of ganglion cells in an isolated mammalian retina. J. Neurophysiol. 39: $1220-1235$.

Millar, T., I. Ishimoto, C. D. Johnson, M. L. Epstein, I. W. Chubb, and I. G. Morgan (1985) Cholinergic and acetylcholinesterase-containing neurons of the chicken retina. Neurosci. Lett. 61: 311-316.

Neal, M. J. (1983) Cholinergic mechanisms in the vertebrate retina. In Progress in Retinal Research, Vol. 2, N. N. Osborne and G. J. Chader, eds., pp. 191-212, Pergamon, Oxford.

Nef, P., C. Oneyser, C. Alliod, S. Couturier, and M. Ballivet (1988) Genes expressed in the brain define three distinct neuronal nicotinic acetylcholine receptors. EMBO J. 7: 595-601.

Ogden, D. C., P. T. A. Gray, D. Colquhoun, and H. P. Rang (1984) Kinetics of acetylcholine activated ion channels in chick ciliary ganglion neurons grown in tissue culture. Pfluegers Arch. 400: 44-50.

Puro, D. G. (1985) Cholinergic systems. In Retinal Transmitters and Modulators: Models for the Brain, Vol. 1, W. W. Morgan, ed., pp. 63-91, CRC, Boca Raton, FL.

Ravdin, P. M., and D. K. Berg (1979) Inhibition of neuronal acetylcholine sensitivity by $\alpha$-toxins from Bungarus multicinctus venom. Proc. Natl. Acad. Sci. USA 76: 2072-2076.

Sah, D. W. Y., R. H. Loring, and R. E. Zigmond (1987) Long-term blockade by toxin $\mathrm{F}$ of nicotinic synaptic potentials in cultured sympathetic neurons. Neuroscience 20:867-874.

Schoepfer, R., P. Whiting, F. Esch, R. Blocker, S. Shimasaki, and J. Lindstrom (1988) cDNA clones coding for the structural subunit of a chicken brain nicotinic acetylcholine receptor. Neuron 1: 241-248.

Spira, A. W., T. J. Millar, I. Ishimoto, M. L. Epstein, C. D. Johnson, J. L. Dahl, and I. G. Morgan (1987) Localization of choline acetyltransferase-like immunoreactivity in the embryonic chick retina. J. Comp. Neurol. 260: 526-538.

Sternberger, L. A. (1979) Immunocytochemistry, 2nd ed., Wiley, New York.

Sugiyama, H., M. P. Daniels, and M. Nirenberg (1977) Muscarinic acetylcholine receptors of the developing retina. Proc. Natl. Acad. Sci. USA 74: 5524-5528.
Vogel, Z., and M. Nirenberg (1976) Localization of acetylcholine receptors during synaptogenesis in retina. Proc. Natl. Acad. Sci. USA 73: 1806-1810.

Vogel, Z., G. J. Maloney, A. Ling, and M. P. Daniels (1977) Identification of synaptic acetylcholine receptor sites in retina with peroxidase-labeled $\alpha$-bungarotoxin. Proc. Natl. Acad. Sci. USA 74: 32683272.

Wada, K., M. Ballivet, J. Boulter, J. Connolly, E. Wada, E. S. Denaris, L. W. Swanson, S. Heinemann, and J. Patrick (1988) Functional expression of a new pharmacological subtype of brain nicotinic acetylcholine receptor. Science 240:330-334.

Wang, G. K., and J. Schmidt (1976) Receptors for $\alpha$-bungarotoxin in the developing visual system of the chick. Brain Res. 114: 524-529.

Whiting, P., and J. Lindstrom (1986a) Purification and characterization of a nicotinic acetylcholine receptor from chick brain. Biochemistry 25: 2082-2093.

Whiting, P., and J. Lindstrom (1986b) Pharmacological properties of immunoisolated neuronal nicotinic receptor. J. Neurosci. 6: 30613069.

Whiting, P., and J. Lindstrom (1987) Purification and characterization of a nicotinic acetylcholine receptor from rat brain. Proc. Natl. Acad. Sci. USA 84: 595-599.

Whiting, P. J., R. Liu, B. J. Morely, and J. M. Lindstrom (1987) Structurally different neuronal nicotinic acetylcholine receptor subtypes purified and characterized using monoclonal antibodies. J. Neurosci. 7: 4005-4016.

Wolf, K. M., A. Ciarleglio, and V. A. Chiappinelli (1988) $\kappa$-Bungarotoxin binding of a neuronal nicotinic receptor antagonist to chick optic lobe and skeletal muscle. Brain Res. 439: 249-258.

Yazulla, S., and J. Schmidt (1977) Two types of receptors for bungarotoxin in the synaptic layers of the pigeon retina. Brain Res. 138: 45-57.

Zamboni, L., and C. Demartino (1967) Buffered picric acid-formaldehyde: A new rapid fixative for electron microscopy. J. Cell Biol. 35: 148a. 